\title{
Has Demonetisation Pushed Digitalisation in India? Some Counter Evidences
}

\author{
M. Nithin ${ }^{1 *}$, P. Jijin ${ }^{1}$ and P. Baiju ${ }^{2}$ \\ 'Research Scholar, School of Economics, University of Hyderabad, Telengana - 500046, India \\ write2nithinm@gmail.com, jijinpandikasala@gmail.com \\ ${ }^{2}$ Research Scholar, Department of Humanities and Sciences, National Institute of Technology - Goa (NIT), \\ Farmagudi, Ponda - 403401, Goa, India; baijupkunnupapa@gmail.com
}

\begin{abstract}
India witnessed demonetisation in November 2016, when high value denomination notes of Rs. 500 and Rs. 1000 were withdrawn at a single stroke which extinguished about 86 percent of the total currency value in circulation. Demonetisation which aimed to curb black money, terror funding and counterfeiting at the first place, was later projected as the government's push for digitalisation drive. In this paper, we analyse the effect of demonetisation on digital payments viz. debit card, point of sale transactions, and mobile transactions using an intervention analysis of time series. The findings of the Study negate the impact of demonetisation on digitalisation of the Indian economy.
\end{abstract}

Keywords: Demonetisation, Digitalisation, Intervention Analysis, Pulse-Function, Step-Function

JEL classification: E42, C01, C21, G28

\section{Introduction}

India experienced its third episode ${ }^{\mathrm{a}}$ of demonetisation in November 2016, when high valued denomination notes of Rs. 500 and Rs. 1000 were withdrawn at a single stroke which extinguished about 86 percent of the total currency value in circulation. Though the act of demonetisation was not unprecedented in its own history, the way it was executed took many by surprise and drew widespread criticisms both from academia and public. Demonetisation which aimed to curb black money, terror funding and counterfeiting at the first place, was later projected as the government's push for digitalisation drive. Ever since then, the earlier objectives have taken a backseat and pushing India towards a cashless economy seems to be the prime objective. It was presented as a panacea and claimed that move towards cashless economy will address the problems of unequal exchange. The government seems to make people believe that demonetisation is the magic wand to push the economy to a cashless society. In this act of haste, the government even seems to have forgotten about the necessary infrastructure needed to realise the 'dream' of a cashless society and also about the cash dependent nature of the people. According to the World Bank Global Findex Data, in India, a meagre 4 percent of the total wage recipients (aged 15 years and above) reported using a bank account to receive wages in 2014. The share was even lower for rural areas at 2.96 percent. Among the poorest 40 percent of the households, only 1.7 percent of the adults reported the use of an account to receive wages in the previous year. These figures clearly suggest that cashless payment constitute only a minuscule share of the total transactions in the Indian economy.

Post-demonetisation, the government and the Reserve Bank of India seem to promote the use of digital payments. There are mainly five modes of transactions that are increasingly being promoted. These are Unified Payment Interface (UPI), Unstructured Supplementary Service Data (USSD), Aadhaar Enabled Payment System (AEPS), mobile wallets and debit cards. Amongst these modes, UPI, USSD and AEPS are introduced and implemented exclusively by the government. However, the growth of

*Author for correspondence 
digital payments remains confined to a small section of the society $\frac{1,31}{\text {. }}$.

The digital methods of payments have seen a drastic increase over the past few years. This is further strengthened by the financial inclusion drive and growing popularity of debit cards. The already growing trend of rising digital transactions was further necessitated when the move to extinguish 86 percent of the total currency value in circulation was announced. One year down the line, it is high time to analyse the effects of demonetisation in enhancing the digital transactions in the economy. The Study seeks to examine whether the impact of demonetisation was a one-time change or of permanent nature.

\section{Objectives}

- To analyse the trend of payment instruments for the transactions.

- To find the impact of demonetisation on the usage of payment instruments.

\section{Data and Methodology}

The study uses monthly data from April 2011 to December 2017 from RBI's website. The variables used in the study are the total value of card transactions, the total value of point of sale $(\mathrm{PoS})$ transactions, the total value of ATM transactions, the total value of mobile transactions (includes mobile wallet and mobile banking transactions) and the total value of Immediate Payment Service (IMPS) transactions. All the variables have been converted into percentage terms by dividing them by the total value of transactions.

The effect of demonetisation on the above variables that measure the extent of digitalisation is analysed by using the method of Intervention Analysis in Time Series (ITSA). Intervention analysis in time series refers to the analysis of how the mean level of a series changes after an intervention when it is assumed that the same Autoregressive Integrated Moving Average (ARIMA) structure for the series holds both before and after the intervention. Intervention analysis has been successfully used to study the impact of air pollution control and economic policies ${ }^{2}$, the impact of Arab oil embargo ${ }^{3}$ and in several other areas ${ }^{29,30}$.

There are two common types of intervention variables: step-function and pulse-function. The former represents an intervention occurring at time $\mathrm{T}$ that remains in effect thereafter while in the latter case the effect is a one-time phenomenon.

Suppose that the ARIMA model for $x_{t}$ (the observed series) with no intervention is

$$
x_{t}-\mu=\omega_{t} \frac{\Theta(B)}{\Phi(B)}
$$

$\mu$ being the mean of the series, $\omega_{t}$ is error series with usual assumptions.

$\Theta(B)$ is the usual Moving Average (MA) polynomial and $\Phi(B)$ is the usual Auto Regressive (AR) polynomial.

Let $z_{\mathrm{t}}=$ the amount of change at time $t$ that is attributable to the intervention. By definition, $z_{\mathrm{t}}=0$ before time $\mathrm{T}$ (time of the intervention). The value of $z_{\mathrm{t}}$ may or may not be 0 after time $\mathrm{T}$.

Then the overall model, including the intervention effect, may be written as

$$
x_{t}-\mu=z_{t}+\omega_{t} \frac{\Theta(B)}{\Phi(B)}
$$

Mainly two types of intervention models are used in this study. These are

(i) Constant permanent change (step-function)

A constant permanent change equal to $\delta$ after the intervention can be written as

$$
\mathrm{Z}_{\mathrm{t}}=\delta \mathrm{I}_{\mathrm{t}}
$$

Thus $\mathrm{Z}_{\mathrm{t}}=\delta$ for all $\mathrm{t} \geq \mathrm{T}$ and $\mathrm{Z}_{\mathrm{t}}=0$ for $\mathrm{t} \leq \mathrm{T}$

(ii) An immediate change that eventually returns to zero (pulse-function)

This can be modelled as follows

$$
\mathrm{Z}_{t}=\frac{\delta}{1-\omega_{t} B} P_{t}
$$

with $P_{\mathrm{t}}=1$ when $t=\mathrm{T}$ and $P_{\mathrm{t}}=0$ otherwise. Assume $\left|\omega_{\mathrm{t}}\right|<1$.

When there is only one group under study (no comparison groups) the standard ITSA regression model assumes the following form $\frac{4-7,33}{}$.

$$
\mathrm{Y}_{\mathrm{t}}=\beta_{0}+\beta_{1} \mathrm{~T}_{\mathrm{t}}+\beta_{2} \mathrm{X}_{\mathrm{t}}+\beta_{3} \mathrm{X}_{\mathrm{t}} * \mathrm{~T}_{\mathrm{t}}+\xi_{\mathrm{t}}
$$


where, $\beta_{0}$ : intercept; $\beta_{1}$ : slope prior to intervention; $\beta_{2}$ : change in level in the period immediately following intervention initiation (compared to counterfactual); $\beta_{3}$ : the difference between pre- and post-intervention. slopes and $\xi_{\mathrm{t}}$ is the normal white noise error term.

\section{Review of Literature}

This section provides an overview of previous research on demonetisation and the E-payment system in India.

The prime objective of demonetisation was to purge "black money" from the economy, generated by income that has not been declared to the the tax authorities, reduce corruption and also to reduce the number of counterfeit notes in circulation that are used to fund terrorist activities ${ }^{8.9}$. Paramahamsa ${ }^{\frac{8}{8}}$ states that demonetisation has been a radical step with short-term costs and longterm benefits. Follow-up actions such as remonetisation, further tax reforms, including bringing land and real estate into the realm of Goods and Services Tax, reducing tax rates and stamp duties, etc. would minimize the costs and maximise the benefits of demonetisation and would also allow growth to return to its trend value in 2017-18, following a temporary decline in 2016-17. Kawadia and Gupta $^{4}$ finds that both fiscal and monetary variables of the economy have improved in post demonetisation period. Fiscal deficit and revenue deficit shrunk as an effect of an increase in the net tax revenue to GDP in the third quarter. The value of rupee appreciated following demonetisation and the pace of inflation also decreased.

According to a recent RBI Report, demonetisation has impacted various sectors of the economy in varying degrees; however, in the affected sectors, the adverse impact was transient and felt mainly in November and December 2016. While demonetisation posed a negative risk to the growth in gross value added, its impact on inflation mainly stemmed from moderation in food inflation. It also had a significant impact on the balance sheet of commercial banks as well as in financial markets which however, was transient $\stackrel{乛}{ }$.

Demonetisation had a significant adverse impact on the informal sector, especially of low-income households and small business units ${ }^{11}$. Some retail outlets were affected severely and experienced a fall in their sales, profits and orders $\frac{12,25}{}$. Ghosh $\frac{13}{13}$ develops a macro-theoretic model to examine the likely impact of demonetisation in India and states that it affected the poorer segments of the people the most. This paper validates that demonetisation is likely to bring about a cumulative decline in output levels in both the organised and the unorganised sectors. The intensity of the decline depends upon how fast the economy is remonetised. If it is delayed, the contraction in output levels may cause considerable harm to the masses. The author suggests a closer attention should have been paid on the informal sector before rushing to such a policy formulation, mainly because the short-term changes in this sector are beyond the government radar.

The government was criticised for coming up with digital promotion as an afterthought when the stated objective of eliminating black money was not met. This is probably the first time in India that the Union Budget focused specifically on digital economy initiatives. Significant and revolutionary developments have taken place in the recent past like launch of digital wallets such as Paytm, Mobiwik, Free Charge and the UPI initiative and BHIM app of the government for smooth transition to digital payments ${ }^{14}$. Technologies such as India's biometric identification system-Aadhaar, do in principle help unbanked citizens obtain a digital identity needed to transact in a cashless economy ${ }^{15}$.

Paramahamsa ${ }^{9}$ points out that the digital transactions amongst new users (RuPay/AEPS) increased sharply; existing users' transactions increased in line with the historical trend because people found it to be a more convenient way to transact. Hence, demonetisation created a network effect among all who insisted to digitalise their transactions. It also argues that digital revolution will continue even after some people return to cash transactions as the supply normalises. Gaur and Padiya ${ }^{16}$ also observed a huge surge in the usage of E-wallet and mobile payments immediately after demonetisation. They also expect a positive result in the long run after the negative effect on the GDP growth for two financial quarters following demonetisation. The most favourable effect of demonetisation is that the economy is taking a step towards digitalisation and cashless economy ${ }^{17,18}$. Adopting cashless instruments certainly implies that there will be a check on the black money.

The measures initiated by the government of India and RBI to push cashless transactions saw a sharp rise in digital payments which was a positive upshot of demonetisation ${ }^{8,19}$. However, it should be mentioned here that RBI seems to have missed the point by considering only the value and volume of digital transactions and 
not the share of digital transactions in total transactions which gives a different picture.

Deshpande ${ }^{20}$ observed that demonetisation offered customers the option of paying through the PoS machines or online merchandising and forced retail business to adopt electronic payments due to shortage of cash. There was a 267 percent surge in the number of daily transactions through E-wallets in the month following demonetisation which was aided by unavailability of cash, and the growth in such transactions levelled to a more moderate pace, once currency became more readily available.

Overall digital transactions of all banks, six months after the demonetisation exercise, exhibited a decline. At the same time, the number of cash withdrawals from ATMs was overtaking transactions at the PoS terminals, while the average value of such withdrawals was also increasing 21 .

Masiero $^{\frac{15}{5}}$ studies the viability of "demonetisation through digitalisation" by examining the impact of demonetisation on digital finance providers and informal street sellers in Bangalore. He argues that digital tools seem to contribute only minimally to their integration in the new cashless system. Customers have a moderate level of satisfaction in E-banking services ${ }^{22}$ while Varsha and Thulasiram ${ }^{23}$ find a high level of acceptance in a study based on consumer behaviour towards the acceptance of E-wallet services in Trichy and Thanjavur districts of Tamil Nadu.

Banaji ${ }^{24}$ stands for the need to recognise the disenfranchising nature of large scale digitisation of nations and reiterates that enforced digitisation in India is being driven by three impulses viz., overwhelming wish to appear modern and on par with the West; deliver millions of poor Indians into the hands of financial institutions, banks and online marketers; and citizen surveillance. The Study also argues for the need to recognise the dangerous rhetorics and propaganda that preface and accompany large scale digitisation of nations and economies. The world is moving towards an automated payment system that is compatible with international standards, but a growing number of security concerns are also hindering its popularity $\underline{25}$.

The effect of demonetisation policy in India was analysed by Singh, Sawhney, Kahlon ${ }^{26}$ using the concept of sentiment analysis. The analysis shows that a large proportion of Indians were happy with this policy. During the initial days, sentiments were more unfavourable towards this policy as the common man had to suffer hardships.
Ultimately, as the new currency notes were made available, the overall sentiment of people became positive. This has been theoretically clarified by Jayakumar ${ }^{21}$ in an attempt to explain the demonetisation exercise as a large-scale "behavioural experiment". This action seems to alter social behaviour by encouraging or even incentivising financial inclusion and a less cash-dependent economy because holding cash has behavioural aspects. But demonetisation failed to take into account the different aspects of utility, i.e. decision utility and experienced utility. Supporters of this policy pointed that the absence of riots during demonetisation and patience of the common Indian braving long queues were expressions in support of the Prime Minister's initiative. These reactions, however, merely represented decision utilities and in no way revealed the true attitude of economic agents towards demonetisation. The government attempted to use a positive empirical scientific frame in this decision by calling for a more prosperous, corruption free economy and also moral frame by demonstrating "standing in queues" as one's patriotism. However, the immediate aftermath of demonetisation was associated with a significant negative frame and thus, the government failed to create tangible positive frames (through nudges) for attitudinal change among the masses.

Effective implantation might have undoubtedly resulted in significant progress towards the Digital India Vision ${ }^{27}$. The shifting process could be weakened by lack of ground level improvement such as advancement in the field of technology and infrastructure, access and awareness among people and digital literacy. Security features, of these E-payment systems also need to inspire trust to continue the process of digitalisation ${ }^{9}$. Forcing poor people to adopt cashless transactions rather than addressing the above mentioned factors is not only unfair and undemocratic but it can also crash the economy.

From the above review process, it is observed that most of the studies focused on the general impact of demonetisation. These lack deep understanding of the effect of demonetisation on digital payment system in India especially in the long run.

\section{Analysis and Discussion}

In this section, we examine the trend in growth of various payment instruments as a percentage of total transactions in value terms. We also employ an intervention analysis to estimate the impact of demonetisation on the growth of these variables. 
Figure 1 shows the trend of usage of various payment instruments in India. It can be seen that there is growing popularity for mobile and PoS transactions in the recent years. It is observed that while usage of cards and ATMs reduced in the immediate month following demonetisation, the digital payment instruments such as mobile payments, PoS transactions and IMPS registered a significant growth. However, this trend is reversed in the month following demonetisation as cash found its way back to the system. Further, the share of digital payments in total value of transactions started declining and cash again becoming the preferred payment medium.

From Table 1, it is observed that all the variables exhibit strong seasonality. It is also observed that PoS and mobile banking are integrated of order one, and IMPS is integrated of order two, while ATM and card value are integrated of order zero.

If rising card value (as a percentage of transactions value) is taken as a sign of digitalisation, it would be a hasty conclusion. This is because the total value of card transactions is composed of total transactions at PoS terminals and at ATMs. From the above (Table 2) analysis
Table 1. ARIMA Structure of Payment Instrument Variables

\begin{tabular}{|c|c|c|}
\hline $\begin{array}{l}\text { Sl. } \\
\text { No }\end{array}$ & Variables & $\begin{array}{c}\text { SARIMA* Structure }^{*}(\mathrm{p}, \mathrm{d}, \mathrm{q}) \times \\
(\mathrm{p}, \mathrm{d}, \mathrm{q})^{12}\end{array}$ \\
\hline 1 & ATM & $(3,0,0) \times(0,0,1)$ \\
\hline 2 & PoS & $(2,1,3) \times(0,1,1)$ \\
\hline 3 & Card Value & $(3,0,0) \times(0,0,1)$ \\
\hline 4 & Mobile Banking & $(0,1,2) \times(0,1,1)$ \\
\hline 5 & IMPS & $(3,2,3) \times(1,2,1)$ \\
\hline
\end{tabular}

Source: Author's Estimation; * Seasonal Auto-regressive Integrated Moving Average

Table 2. ITSA of PoS (As a Percentage of Total Transactions Value)

\begin{tabular}{|c|c|c|}
\hline Parameters & Coefficient & P-value \\
\hline$\beta_{1}$ & .002 & 0.00 \\
\hline$\beta_{2}$ & .132 & 0.00 \\
\hline$\beta_{3}$ & -.003 & 0.43 \\
\hline$\beta_{0}$ & .124 & 0.00 \\
\hline Treated: $\beta_{1}+\beta_{3}$ & -0.0008 & 0.79 \\
\hline
\end{tabular}

Source: Author's Estimation

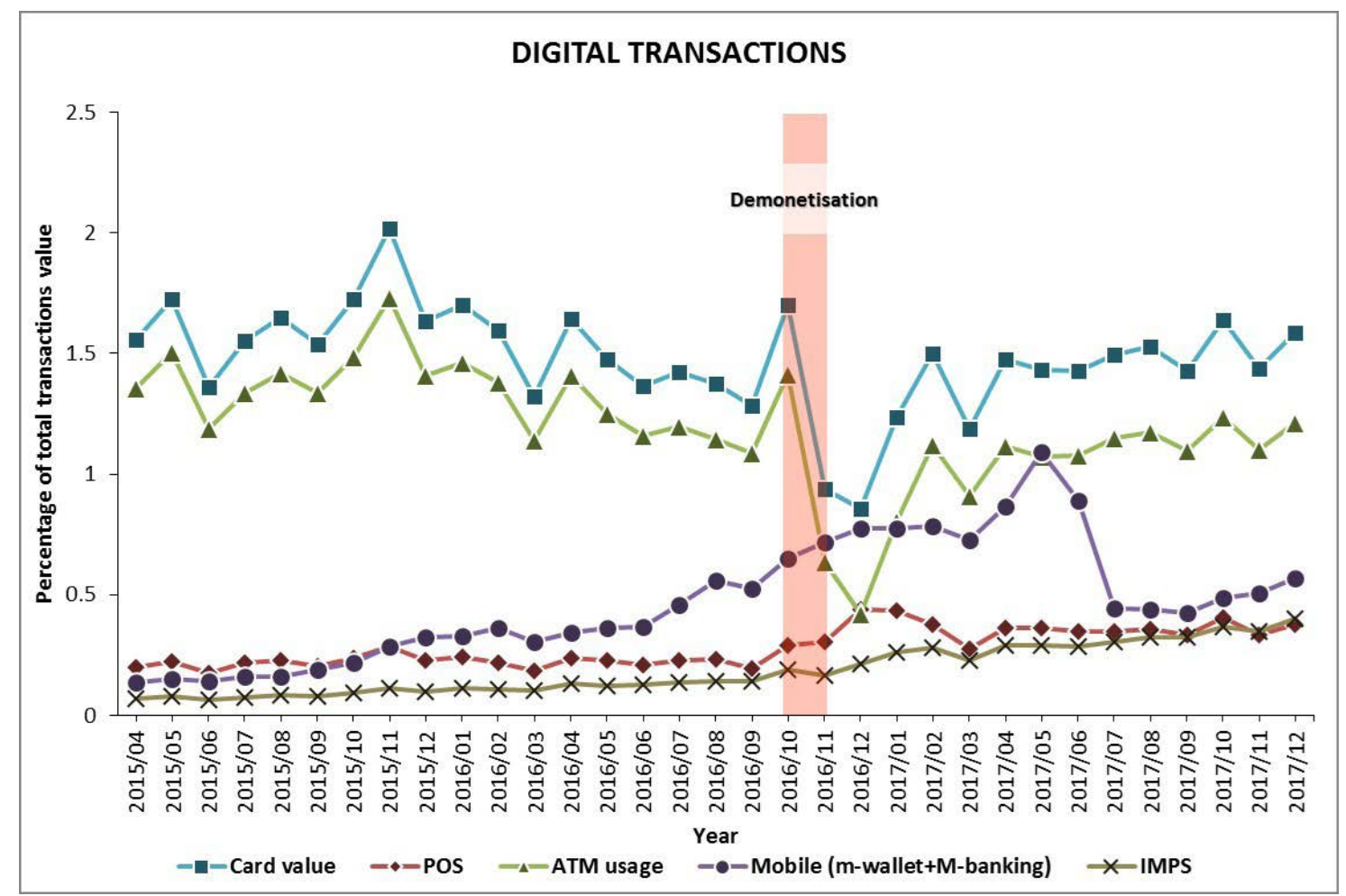

Source: RBI Data Warehouse

Figure 1. Trend of Payment Instruments (As a Percentage of Total Transactions Value) 
of PoS transactions, we can observe that though the value of PoS transactions increased sharply immediately following demonetisation, it decreased thereafter but the fall is not statistically significant. The lower coefficients post domonetisation can be due to fewer data points. Thus, the results show that demonetisation has in fact not increased PoS transactions as a percentage of transactions value, to the extent expected from a digitalisation drive.

From Figure 2, it is observed that PoS transactions were increasing slowly throughout the period before demonetisation. These transactions increased in the immediate month following demonetisation due to restricted cash. However, as cash found its way back to the system, PoS transactions started to decline.

The total card value usage also consists of usage at ATMs. A fall in the value of transactions at ATMs can be seen as an indicator for digitalisation while an increase in the value indicates a preference for cash over digital payments as ATMs are still predominantly used for withdrawing cash. From Table 3, it can be observed that while there was as a significant decrease
Table 3. ITSA of ATM Usage (As a Percentage of Total Transactions Value)

\begin{tabular}{|c|c|c|}
\hline Parameters & Coefficient & P-value \\
\hline$\beta_{1}$ & 0.0008 & 0.44 \\
\hline$\beta_{2}$ & -0.618 & 0.00 \\
\hline$\beta_{3}$ & 0.044 & 0.00 \\
\hline$\beta_{0}$ & 1.288 & 0.00 \\
\hline Treated: $\beta_{1}+\beta_{3}$ & 0.045 & 0.00 \\
\hline
\end{tabular}

Source: Author's Estimation

in ATM transactions in the immediate month post demonetisation, the ATM transactions seem to increased at a higher rate than their growth in the period preceding demonetisation. It must also be noted that the decrease in ATM transactions in the month of demonetisation was partly due to the withdrawing limits imposed, empty ATMs and large queues in front of ATMs.

From Figure 3, it can be observed that before demonetisation ATM transactions were increasing, while

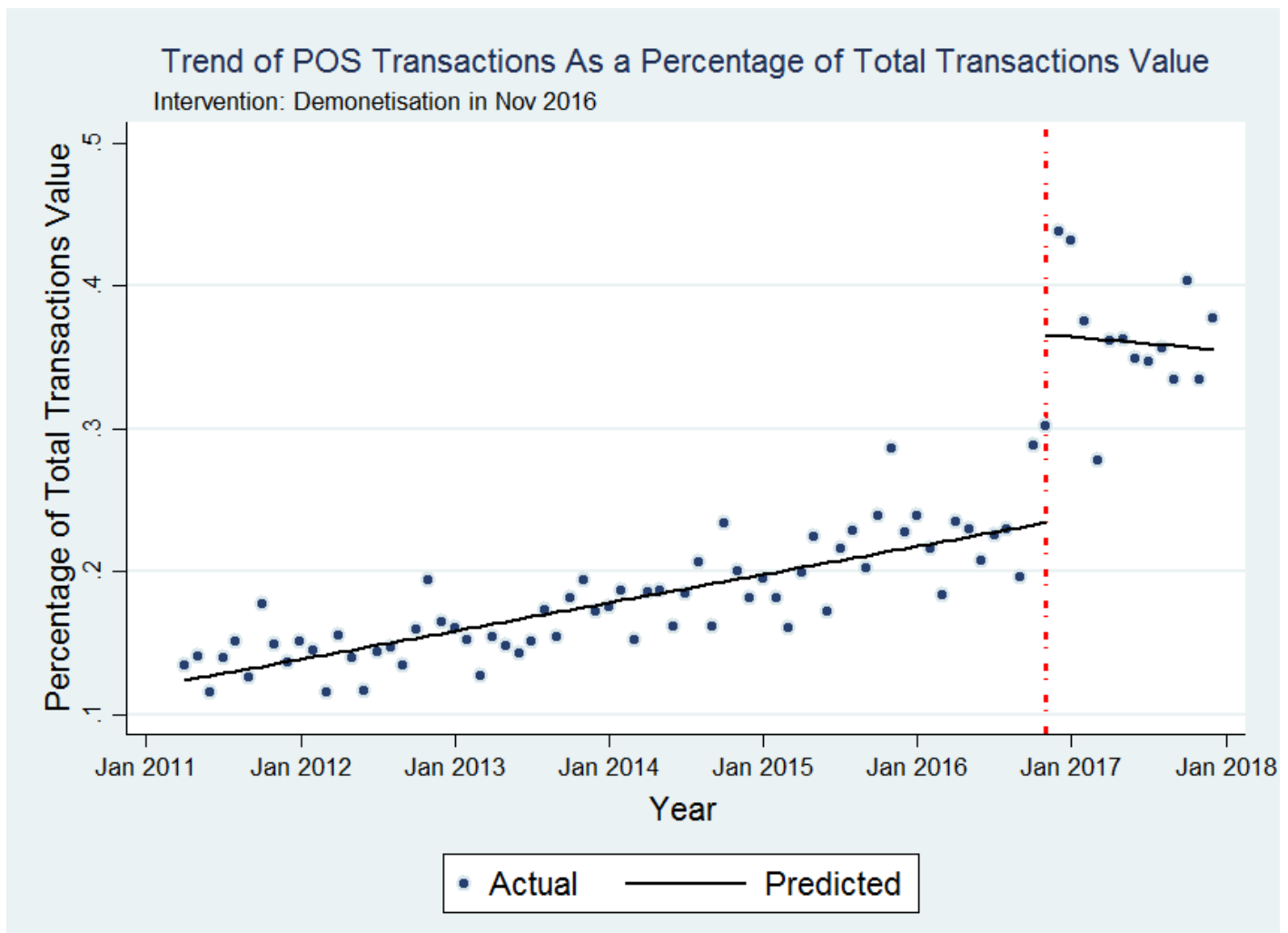

Source: RBI's Data Warehouse and Author's Estimation

Figure 2. Trend of PoS Transactions (As a Percentage of Total Transactions Value) 


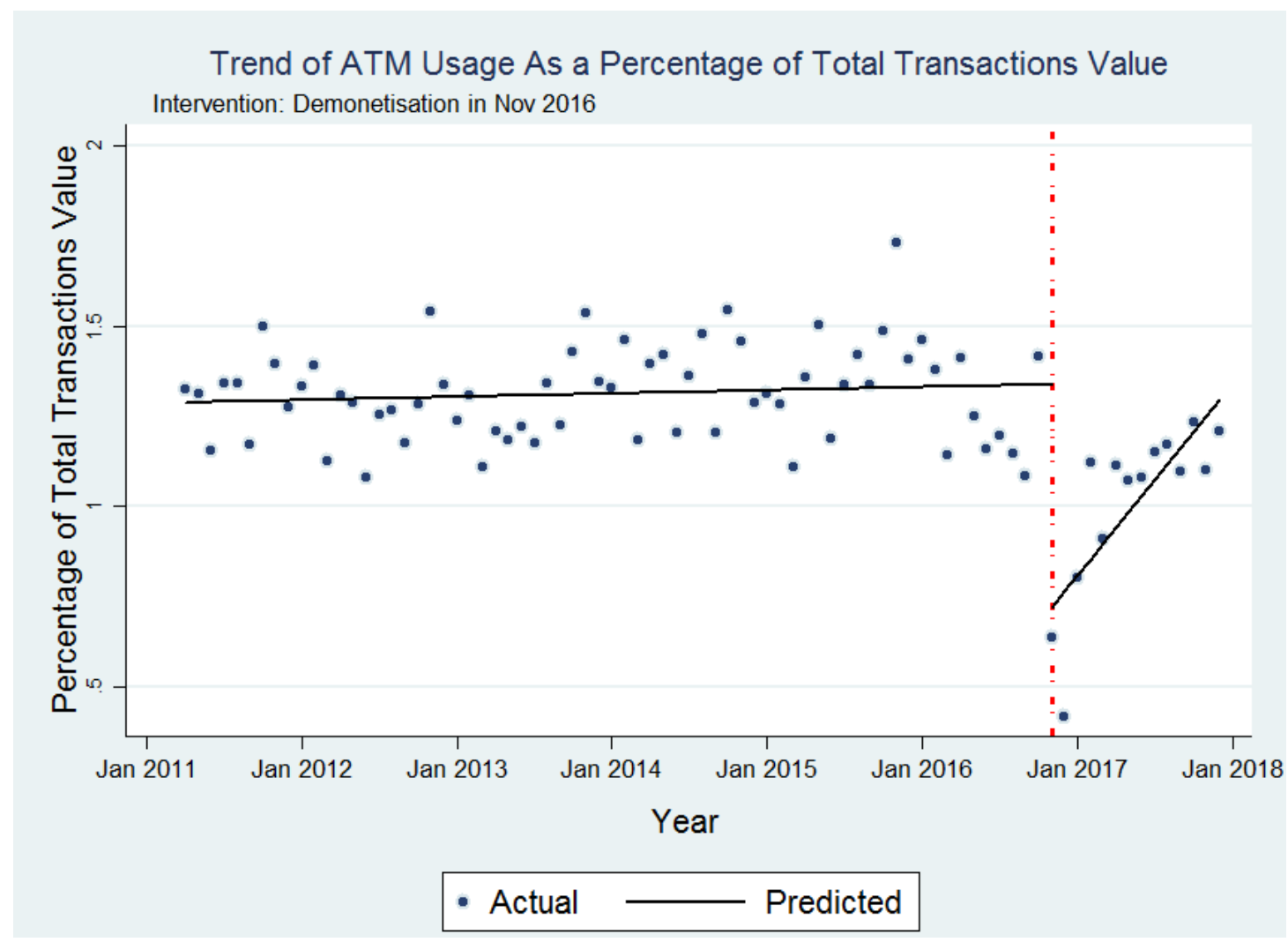

Source: RBI's Data Warehouse and Author's Estimation

Figure 3. Trend of ATM Usage (As a Percentage of Total Transactions Value)

there was a significant decrease in ATM transactions in the immediate month of demonetisation. As new currency got into the system and once ATMs were recalibrated, they started to increase again.

From the above regression in Table 4, it can be seen that initial level of card value as a percentage of transactions is 1.412 and it appears to have increased every year by a negligible 0.003 percent before demonetisation. Immediately following demonetisation, the card value as

Table 4. ITSA of Card Value (As a Percentage of Total Transactions Value)

\begin{tabular}{|c|c|c|}
\hline Parameters & Coefficient & P-value \\
\hline$\beta_{1}$ & 0.003 & 0.03 \\
\hline$\beta_{2}$ & -0.486 & 0.00 \\
\hline$\beta_{3}$ & 0.042 & 0.00 \\
\hline$\beta_{0}$ & 1.412 & 0.00 \\
\hline Treated: $\beta_{1}+\beta_{3}$ & 0.044 & 0.00 \\
\hline
\end{tabular}

Source: Author's Estimation a percentage of transaction value, fell by 0.486 percent mainly due to a fall in ATM transactions as observed in Figure 3. However, after demonetisation, the card value as a percentage of total transactions picked up again and this growth is higher than the growth in card transactions before demonetisation, suggesting increased use of cards post demonetisation. This however, shows people's preference for cash, as cards are more commonly used for withdrawing cash than for using at PoS terminals. The rising cash transactions might also be due to the uncertainty posed by the event of demonetisation and subsequent loss of trust in the currency.

From Figure 4, it can be seen that level of card value as a percentage of transactions is increasing in every year before demonetisation. Immediately following demonetisation card value as a percentage of transaction registered a sharp decline. However, after the demonetisation event, the card value as a percentage of transactions increased again and even overshot its predemonetisation level. 


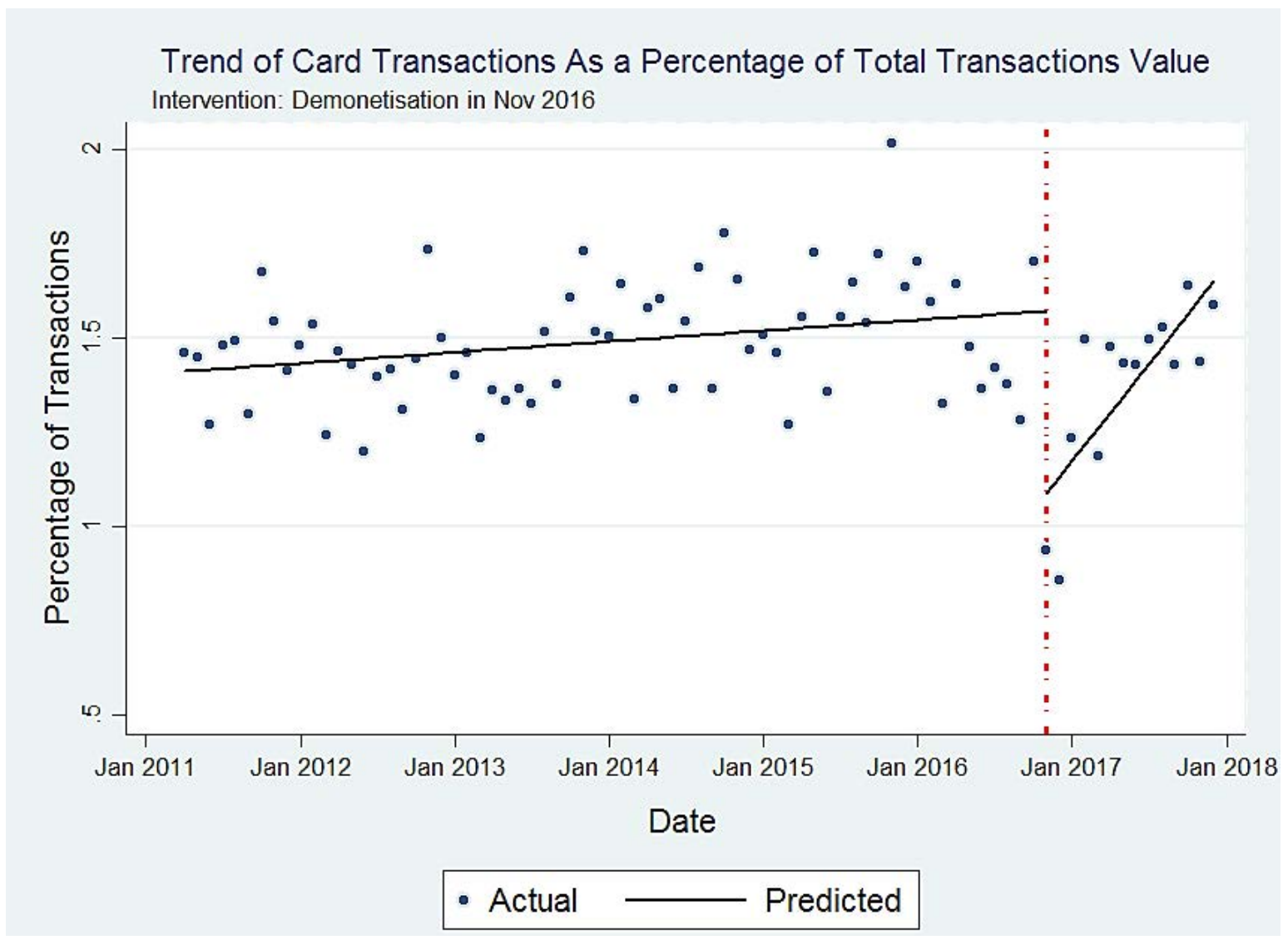

Source: RBI's Data Warehouse, and Author's Estimation

Figure 4. Trend of Card Value (As a Percentage of Total Transactions Value)

Table 5. ITSA of Total Mobile Transactions (As a Percentage of Total Transactions)

\begin{tabular}{|c|c|c|}
\hline Parameters & Coefficient & P-value \\
\hline$\beta_{1}$ & 0.007 & 0.00 \\
\hline$\beta_{2}$ & 0.533 & 0.00 \\
\hline$\beta_{3}$ & -0.035 & 0.00 \\
\hline$\beta_{0}$ & -0.112 & 0.00 \\
\hline Treated: $\beta_{1}+\beta_{3}$ & -0.029 & 0.00 \\
\hline
\end{tabular}

Source: Author's Estimation

Another indicator of digital transactions in the analysis is the value of mobile transactions as a percentage of total transactions value. For the purpose of this analysis, the total value of mobile transactions is taken as the sum of the value of mobile wallets transactions and the value of mobile banking transactions. From the regression Table 5, it can be observed that while there was a significant surge in the usage of mobile transactions in the intervention period, the usage of mobile transactions has declined in periods post-demonetisation. The decline is substantial and statistically significant and is contrary to what was expected of the digitalisation drive.

Figure 5 shows that mobile transaction as a percentage of transactions was also rising, though marginally prior to demonetisation. The immediate month of demonetisation witnessed a sharp increase in mobile transactions as well due to the shortage of currency. However, like other digital payments, mobile banking also witnessed a decline with replenishment of currency in the system.

The last indicator of digital transactions in this analysis is the value of IMPS transactions as a percentage of total transactions. From Table 6, it is observed that IMPS transactions registered a significant increase in the immediate month of demonetisation while the growth in transactions had slowed down since then. But the growth in IMPS transactions post-demonetisation exceeded its growth in periods preceding demonetisation. However, this again cannot be taken as evidence for growing 


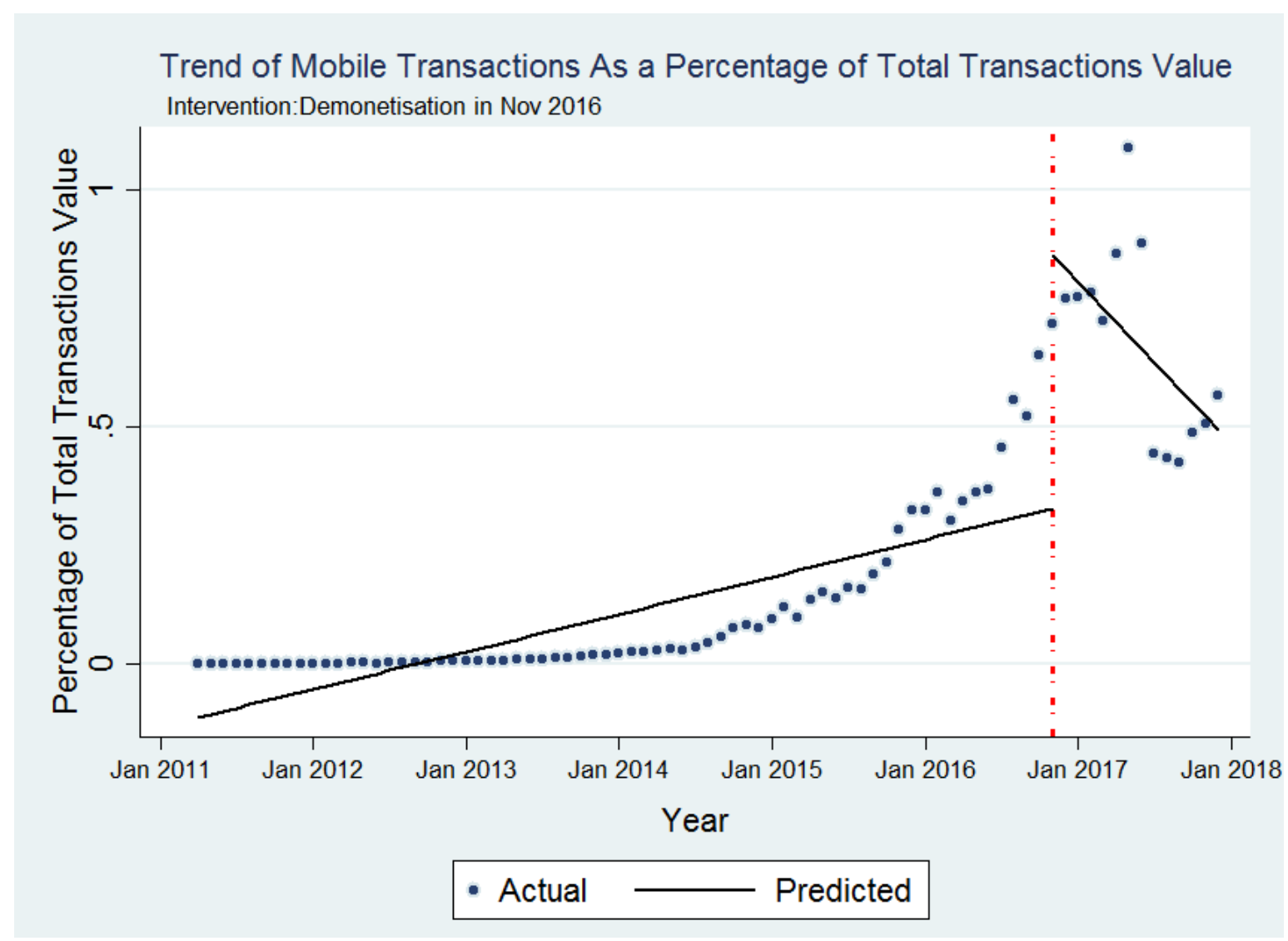

Source: RBI's Data Warehouse, and Author's Estimation

Figure 5. Trend of Mobile Transactions (As a Percentage of Total Transactions Value)

Table 6. ITSA of IMPS Transactions (As a Percentage of Total Transactions Value)

\begin{tabular}{|c|c|c|}
\hline Parameters & Coefficient & P-value \\
\hline$\beta_{1}$ & 0.003 & 0.00 \\
\hline$\beta_{2}$ & 0.088 & 0.00 \\
\hline$\beta_{3}$ & 0.012 & 0.00 \\
\hline$\beta_{0}$ & -0.036 & 0.00 \\
\hline Treated: $\beta_{1}+\beta_{3}$ & 0.014 & 0.00 \\
\hline
\end{tabular}

Source: Author's Estimation

digitalisation as envisaged by the government, because IMPS transactions constitute only a meagre 0.39 percent of the total transactions and is not used as an alternative for cash transactions.

Figure 6 shows that value of IMPS transactions was more or less constant until 2014, when it started to rise. The IMPS transactions as a percentage of transactions value registered a significant rise in the immediate month of demonetisation. Unlike other digital payment instruments, IMPS transactions present a rising trend which is steeper in the post-demonetisation period compared to the pre-demonetisation period.

\section{Conclusion}

The digitalisation drive which was pushed by the government after demonetisation has been subject to debate. Earlier studies have asserted that demonetisation will improve digital transactions of the economy in the long run while many economists were apprehensive of pushing the economy for digitalisation without sufficient infrastructure. The present study finds that while the usage of cards for transactions as a percentage of total transactions has increased, the share of point of sale transactions (PoS) and mobile transactions has registered a decline after demonetisation. The results also indicate a 


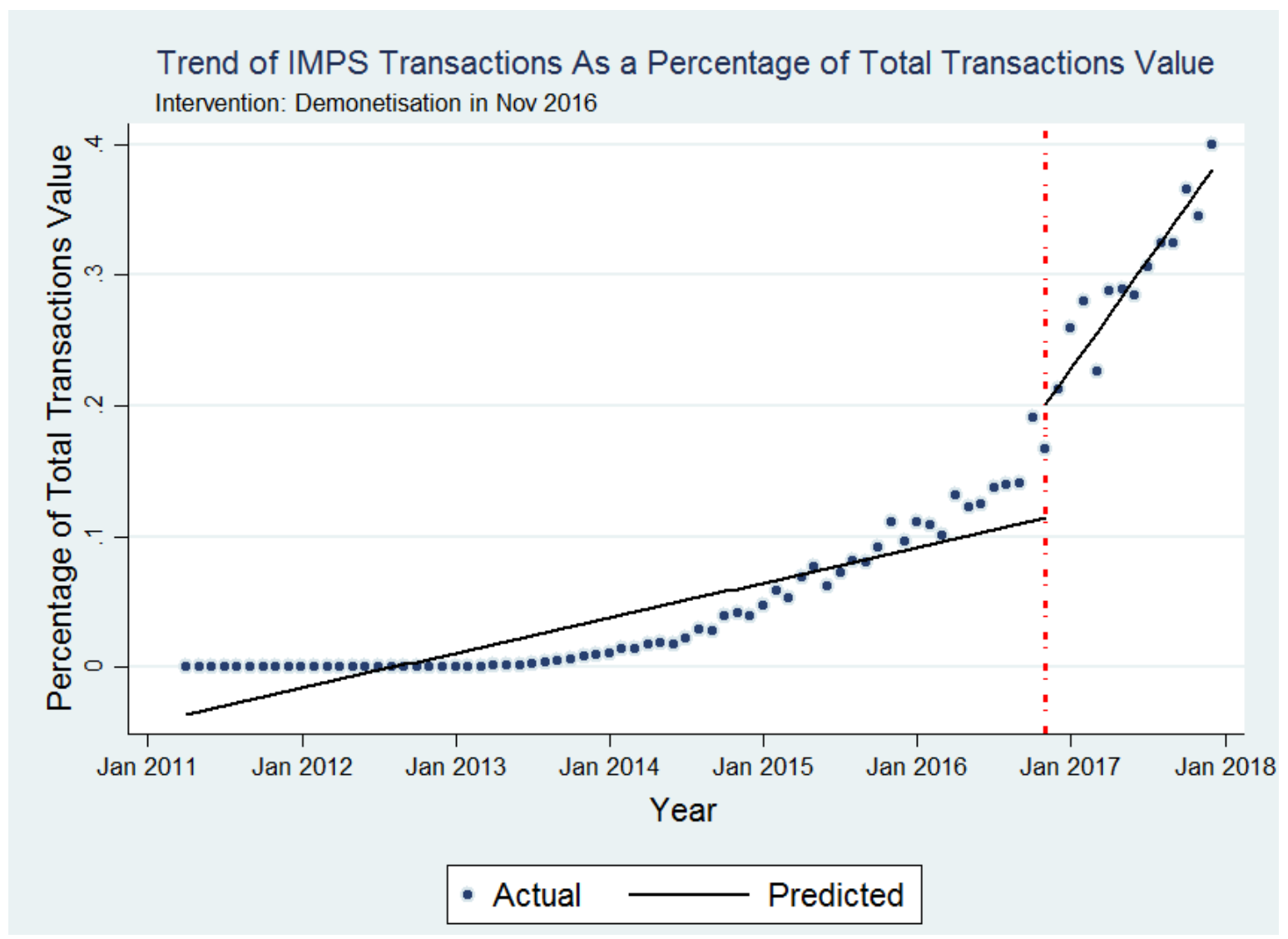

Source: RBI's Data Warehouse and Author's Estimation

Figure 6. Trend of IMPS Transactions (As a Percentage of Total Transactions Value)

faster growth in the percentage share of ATM transactions value while IMPS transactions, as a percentage of total transactions value, have exhibited a marginal rise.

Demonetisation appears to have had a negative net unfavourable impact on digitalisation. This should be examined along with strong promotion by both the government and RBI for a move towards a cashless economy. Low digitalisation in percentage terms might be on account of an economy being 'unripe' to move towards a cashless society due to infrastructural impediments and habit persistence. The results of the Study call for strong government intervention in the form of better infrastructure to promote digital transactions, as lack of necessary infrastructure is a prime reason for lower digitalisation with regard to payment instruments. The Study also argues for a supportive role from the government to help the economy traverse to a world of digital payments. This can be in the form of incentives to use digital transactions like a waiver of service charge or cashbacks which will act as a nudge to move to digital payments unlike the restriction on cash transactions that force people to switch to digital transactions. Other important areas where government intervention is pertinent are financial literacy and financial inclusion. The Study asserts that demonetisation has not helped much in pushing digital payments in India and suggests further improvements in infrastructure and policy environment for the promotion of digital transactions rather than adopting hasty reform measures like demonetisation.

\section{References}

1. Sood and Baruah. The new moral economy. Economic \& Political Weekly, 2017; 52(1): 31.

2. Box GE, Tiao GC. Intervention analysis with applications to economic and environmental problems. Journal of the American Statistical Association; 1975; 70(349):70-9. https://doi.org/10.1080/01621459.1975.10480264 
3. Montgomery DC, Weatherby G. Modeling and forecasting time series using transfer function and intervention methods. AIIE Transactions. 1980;12(4):289-307.

4. Huitema BE, Mckean JW. Design specification issues in time-series intervention models. Educational and Psychological Measurement. 2000; 60(1), 38-58.

5. Linden A, Adams JL. Applying a propensity score-based weighting model to interrupted time series data: improving causal inference in programme evaluation. Journal of evaluation in clinical practice, 2011; 17(6): 1231-8.

6. Simonton DK. Creative productivity, age, and stress: A biographical time-series analysis of 10 classical composers. Journal of Personality and Social Psychology. 1977; 35(11):791-804

7. Simonton DK. Eminence, creativity, and geographical marginality: A recursive structural equation model. Journal of Personality and Social Psychology. 1977: 35(11), 805-16.

8. RBI. Macroeconomic Impact of demonetisation-A preliminary assessment. Occasional Publication; 2017a.

9. Paramahamsa R. Demonetisation: To deify or demonize? Economic Survey; 2017. p. 17.

10. Kawadia G, Gupta, N. Demonetisation: A step for revitalizing Indian economy. Jharkhand Journal of Development and Management Studies. 2017; 15(2):7297-309.

11. Bhattacharya K, Mitra S, Pal S, Saha B. Reviving the informal sector from the throes of demonetisation. South Asia@ LSE; 2017.

12. Agyeman CM, Amoah-Binfoh, K. The Aftermath of a Demonetisation Exercise: A Comparative Evaluation of the Retail Sector, International Journal of Advanced Research in Management and Social Sciences. 2017; 6 (7).

13. Ghosh AN. Impact of demonetisation on India: A macrotheoretic analysis. Trade and Development Review. 2017; 9(1); 57-73.

14. Ali SMS, Akhtar MW, Safiuddin SK. Digital Payments for Rural India-Challenges and Opportunities. International Journal of Applied Economics. 2017; 7(1):31-8.

15. Masiero S. New routes to cashlessness? ICTs, demonetisation, and the Indian informal economy, Development Studies Association Conference: Sustainability interrogated: societies, growth, and social justice (DSA 2017); Bradford. 2017; Sep 6-8;

16. Gaur AD, Padiya J. From Demonetisation to Digitization of Indian Economy: The Road Ahead, Proceedings of International Conference on Strategies in Volatile and Uncertain Environment for Emerging Markets, Indian Institute of Technology Delhi, New Delhi; 2017. p. 598-607.

17. Kawadia G, Gupta N. Demonetisation: A Step for Revitalizing Indian Economy, Jharkhand Journal of Development and Management Studies. 2017; 15(2):7297- 309.
18. Balaji KC, Balaji K. A study on demonetization and its impact on cashless transactions. International Journal of Advanced Scientific Research and Development; 2017. p. 58-64.

19. RBI. Impact of Demonetisation on the Financial Sector, RBI Bulletin; 2017b.

20. Deshpande R. India's demonetisation: Modi's 'nudge' to change economic and social behaviour. Asian Affairs. 2017; 48(2):222-35. https://doi.org/10.1080/03068374.2017.1313 592

21. Jayakumar T. Behavioural economics perspective of 'demonetisation'. Economic and Political Weekly. 2017; 52(41):41.

22. Swaminathan S. Technology enabled banking facilities and satisfaction-customers' view. Namex International Journal of Management Research; 2016. p. 139-43.

23. Varsha R, Thulasiram M. Acceptance of e-wallet services: A study of consumer behavior. International Journal of Innovative Research in Management Studies. 2016; 1(4):2455-7188.

24. Banaji S. India: digitising an unequal world. Parenting for a Digital Future. LSE Blog; 2017.

25. Mridha MF, Nur K, Saha AK, Adnan MA. A new approach to enhance internet banking security. International Journal of Computer Applications. 2017; 160(8).

26. Singh P, Sawhney RS, Kahlon KS. Sentiment analysis of demonetization of 500 \& 1000 rupee banknotes by Indian government. ICT Express; 2017. https://doi.org/10.1016/j. icte.2017.03.001

27. Manazir SH. Union Budget 2017-18: leading India towards a digital economy. South Asia@ LSE; 2017.

28. Rajakumar JD, Shetty SL. Demonetisation: 1978, the Present and the Aftermath. Economic \& Political Weekly. 2016; 51(48):13-17.

29. Leong C, Tan B, Xiao X, Tan FTC, Sun Y. Nurturing a FinTech ecosystem: The case of a youth microloan startup in China. International Journal of Information Management. 2017; 37(2), 92-97. https://doi.org/10.1016/j. ijinfomgt.2016.11.006

30. Linden A. Conducting interrupted time-series analysis for single-and multiple-group comparisons. Stata Journal. 2015; 15(2):480-500.

31. Madureira A. Factors that hinder the success of SIMbased mobile NFC service deployments. Telematics and Informatics. 2017; 34(1):133-50. https://doi.org/10.1016/j. tele.2016.05.003

32. Rani G. Effects of Demonetization on Retail Outlets. International Journal of Applied Research. 2016; 2(12):400-1.

33. Wei WW. Time series analysis: univariate and multivariate methods. Pearson Addison Wesley; 2006. 


\section{Notes:}

${ }^{a}$ The previous two instances of demonetisation took place in 1946 and 1978 3. In 1946, the currency notes of Rs. 1,000 and Rs. 10,000 were removed from circulation. However, the move did not have much impact as the use of such high denomination currency was not widespread and these notes were primarily out of reach of common people. In the second instance of demonetisation in India, the then President of India, Neelam Sanjiva Reddy, promulgated an Ordinance on 16 January, 1978 to phase out high denomination notes of Rs. 1,000, Rs. 5,000 and Rs. 10,000. The objective was to eliminate illegal transactions 21 . The move did not receive much attention as it again had little impact on people's daily life. 